\title{
Thermal behavior of ethylene copolymers with di- and tri-alkenylsilsesquioxane comonomers synthesized by post-metallocene catalysts
}

\author{
Paweł Groch $^{1} \cdot$ Katarzyna Dziubek $^{1} \cdot$ Krystyna Czaja $^{1} \cdot$ Beata Sacher-Majewska $^{1}$
}

Received: 30 August 2019 / Accepted: 24 February 2020 / Published online: 4 March 2020

(c) The Author(s) 2020

\begin{abstract}
This paper reported thermal properties of ethylene copolymers with di- and tri-alkenylsilsesquioxanes (POSS) synthesized by bis(phenoxy-imine) Ti, Zr, V, and V salen-type complexes. Ethylene copolymers with multi-alkenyl POSS obtained by such complexes contain multi-alkenyl POSS incorporated into the polymer chain as a side group. They were characterized by different thermal behavior depending on the kind of multi-alkenyl POSS comonomer, and type of the catalyst used, as well as polymerization conditions and thus the structure of the copolymer chain. Ethylene/POSS copolymers differed in incorporation of POSS into the polymer chain, content of specific unsaturation groups, and molecular weight, as well as heterogeneity of polymer chain compositions. The incorporation of multi-alkenyl POSS into the polymer chain affected melting and crystallization processes of copolymers in different ways. The POSS units could act as a nucleating agent of macromolecules. The increasing POSS content in E/POSS copolymers resulted in increasing thermal stability of obtained products, regardless of the kind of multi-alkenylsilsesquioxanes used. Thermal stability of such copolymers increased with decreasing content of trisubstituted vinylene groups (internal saturations) as well. The highest improvement of thermal stability over $85{ }^{\circ} \mathrm{C}$ in comparison with $\mathrm{PE}$ was observed in case of E/POSS copolymers synthesized by bis(phenoxy-imine) zirconium catalyst. The composition heterogeneity of E/POSS copolymers was found to affect markedly thermal stability of E/POSS copolymers.
\end{abstract}

Keywords Ethylene · Multi-alkenyl polyhedral oligomeric silsesquioxanes (POSS) · Copolymers · Thermal stability · Melting and crystallization process

\section{Introduction}

One of the most promising methods for improving thermal stability of polyolefins is development of new materials containing polyhedral oligomeric silsesquioxanes (POSS) $[1,2]$. POSS are a class of interesting nano-scale units for the synthesis of organic-inorganic hybrid materials [3-9]. Indeed, incorporation of POSS into polymer chain results in improvement of physicochemical properties, such as mechanical properties [10], thermal stability [1], thermooxidative resistance [1], and flammability $[11,12]$ in comparison with unmodified polymers.

Paweł Groch

pawel.groch@uni.opole.pl

1 Faculty of Chemistry, Opole University, Oleska 48, 45-052 Opole, Poland
A typical POSS molecule is composed of a $\mathrm{Si}-\mathrm{O}$ cage and several reactive or unreactive organic groups attached to $\mathrm{Si}$ atoms. POSS compounds containing at least one reactive substituent can be introduced into the polymer chain via polymerization or reactive grafting methods. Monofunctional POSS macromonomers can be incorporated into the polymer chain as pendant side groups, internal and/or end groups in the main chain [6-8].

As regards copolymers of olefins with POSS, many investigations were focused on the effect of the completely condensed silicon-oxygen $\mathrm{T}_{8}$ POSS core with one reactive substituent with cyclopentyl or iso-butyl as non-reactive substituents $[1,13,14]$. Mono-functional POSS units incorporated into the polymer chain improved thermal stability of obtained materials $[8,13,14]$ and could act as nucleating agents, which accelerate crystallization process of copolymers [7].

In case of ethylene copolymers with multi-alkenylsilsesquioxanes up to this moment, there are no literature data 
describing their thermal stability. It should be noted that thermal properties of such materials could depend not only on the kind and incorporation level of POSS comonomer but also on the microstructure of copolymer macromolecules. Ethylene copolymers with multi-alkenyl POSS could differ not only in the kind and number of substituents but also in the type of silicon-oxygen cage. Moreover, the way of POSS incorporation could significantly influence on thermal behavior of obtained polymeric products.

The purpose of the present work was to study comprehensively the influence of the structure of di- and tri-functional silsesquioxane comonomers with different structure of POSS core (completely or incompletely condensed silicon-oxygen cage of POSS) and different substituents attached to POSS core on thermal behavior of ethylene/POSS copolymers synthesized by bis(phenoxy-imine) Ti, Zr, V, and V salen-type complexes. In case of the previous research, it was found that through careful selection of functional POSS comonomer, its amount, type of catalyst, and polymerization conditions (ethylene pressure) make it possible to obtain a polymeric product with different structural characteristics (i.e, molecular weight, type and content of unsaturation groups, heterogeneity of copolymer macromolecules). The relationship between structure and content of multi-alkenylsilsesquioxanes incorporated into the copolymer, as well as the microstructure of copolymer macromolecules and their thermal properties of the products, was determined.

\section{Experimental}

\section{Materials}

Ethylene copolymers with di- and tri-alkenylsilsesquioxane comonomers were prepared according to the procedures as published previously $[4,5]$. The phenyl-substituted di(hex5-enyl) double-decker silsesquioxane (POSS-6-2) and iso-butyl-substituted tri-decenyl-silsesquioxane (POSS10-3) which contained the incompletely condensed silicon-oxygen $\mathrm{T}_{4} \mathrm{D}_{3}$ were used as comonomers (Fig. 1). These POSS compounds were copolymerized with ethylene over bis(phenoxy-imine) $\mathrm{Ti}, \mathrm{Zr}$, and $\mathrm{V}$ as well as $\mathrm{V}$ salen-type complexes are shown in Fig. 2.

E/POSS copolymers had various content of silsesquioxanes incorporated into the polymer chain $\left(\mathrm{C}_{\mathrm{POSS}}\right)$ which fell within the range of 1.03-7.57 mass\%, as determined by the ${ }^{1} \mathrm{H}$ NMR method $[4,5]$. The structure of obtained E/POSS copolymers including different unsaturation groups is shown in Scheme 1.

The relative content of unsaturation groups in the range of 0.321-1.032 and 0.196-1.764 for vinyl $\left(\mathrm{A}_{908 / 2020}\right)$ and trisubstituted vinylene groups $\left(\mathrm{A}_{800 / 2020}\right)$, respectively, was determined by FT-IR method $[4,5]$. Molecular weight $\left(M_{\mathrm{w}}\right)$ for E/POSS copolymers evaluated on an Alliance $135 \mathrm{GPCV}$ 2000 apparatus was in the range of $165-1135 \times 10^{3} \mathrm{~g} \mathrm{~mol}^{-1}$, and it depended on the type of organometallic complex used in (co)polymerization, as well as polyreaction condition [4, 5]. It should be noted that neat polyethylenes obtained under the same conditions were used as reference material.

\section{Thermal properties of E/POSS copolymers}

Thermal stability studies under dynamic (non-isothermal) conditions employed the thermogravimetric analysis (TGA) in air atmosphere (gas flow $50 \mathrm{~mL} \mathrm{~min}^{-1}$ ) with the use of a TG/DSC1 Mettler Toledo device. Before the analysis, the oven of the device was purged with air. (Co)polymer powders $(5 \mathrm{mg})$ were placed in a ceramic pan and heated from (a)

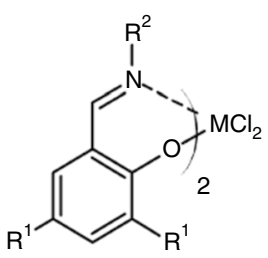

FI-TiH: $R^{1}=\mathrm{H} \mathrm{R}^{2}=$ naphthyl $\mathrm{M}=\mathrm{Ti}$

$\mathrm{Fl}-\mathrm{ZrH}: \mathrm{R}^{1}=\mathrm{H} \mathrm{R}^{2}=$ naphthyl $\mathrm{M}=\mathrm{Zr}$

FI-VBu: $\mathrm{R}^{1}=t$-Bu $\mathrm{R}^{2}=$ phenyl $\mathrm{M}=\mathrm{V}$ (b)

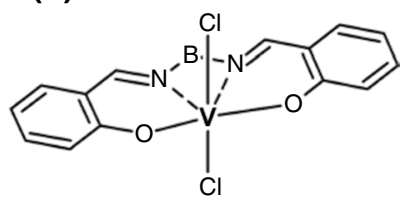

Sal-V:B= $\mathrm{C}_{3} \mathrm{H}_{6}$
Fig. 2 Structures of bis(phenoxy-imine) (a) and salen-type (b) complexes
Fig. 1 Structures of di- (a) and tri- (b) comonomers (a)

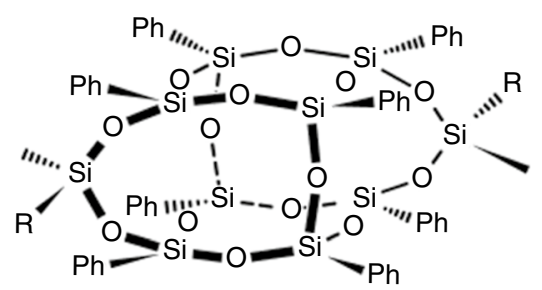

POSS-6-2: $\mathrm{R}=-\mathrm{Si}\left(\mathrm{CH}_{3}\right)_{2} \mathrm{C}_{4} \mathrm{H}_{8} \mathrm{CH}=\mathrm{CH}_{2}$ (b)

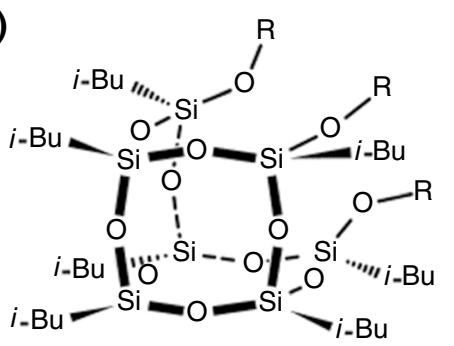

POSS-10-3: $\mathrm{R}=-\mathrm{Si}\left(\mathrm{CH}_{3}\right)_{2} \mathrm{C}_{4} \mathrm{H}_{16} \mathrm{CH}=\mathrm{CH}_{2}$ 

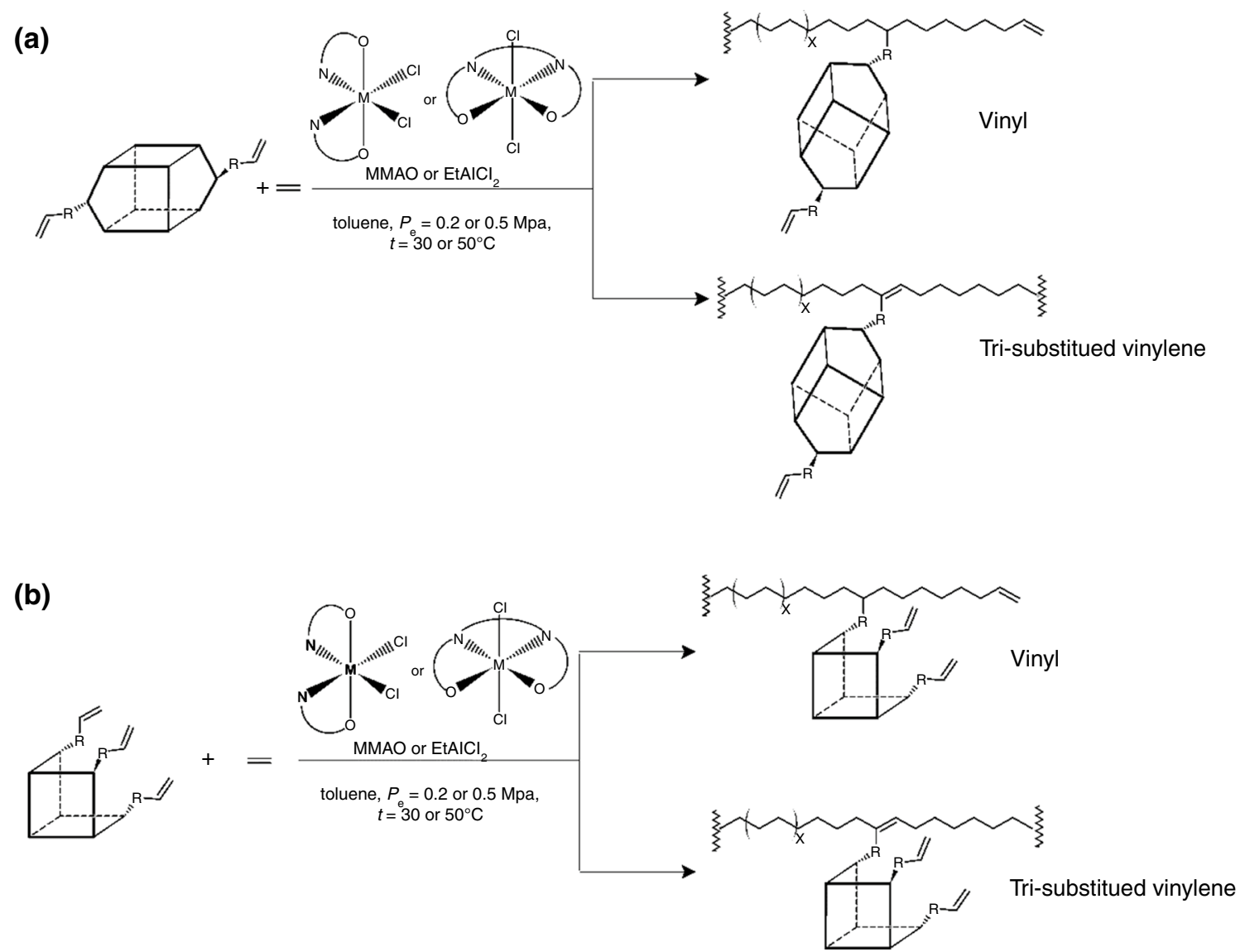

Scheme 1 Schematic structure of ethylene with a di- or $\mathbf{b}$ tri-alkenylsilsesquioxanes obtained over bis(phenoxy-imine) and salen-type complexes including different unsaturation groups

the room temperature up to $500{ }^{\circ} \mathrm{C}$ at the heating rate of $10{ }^{\circ} \mathrm{C} \mathrm{min}{ }^{-1}$. The $T_{5}$ and $T_{30}$ parameters define the temperatures at which 5 and $30 \%$ of the sample mass are lost, respectively, as well as there were determined the temperatures at the maximum rate of weight loss ( $\left.T_{\max }\right)$ for all studied (co) polymers.

Differential scanning calorimetry (DSC) measurements were performed by using a DSC1 Mettler Toledo instrument at the heating and cooling rate of $10{ }^{\circ} \mathrm{C} \mathrm{min}^{-1}$ at nitrogen atmosphere with the gas flow $30 \mathrm{~mL} \mathrm{~min}^{-1}$. Products in an amount of $5 \mathrm{mg}$ were placed in an open aluminum pan $(40 \mu \mathrm{l})$ and heated up to $170{ }^{\circ} \mathrm{C}$, cooled to room temperature, and then heated again to $170{ }^{\circ} \mathrm{C}$ in order to remove their thermal history. The melting temperature $\left(T_{\mathrm{m}}\right)$, crystallization temperature $\left(T_{\mathrm{c}}\right)$, and heat of fusion $\left(\Delta H_{\mathrm{f}}\right)$ values were obtained for the samples formerly melted and recrystallized, which then were heated up to $170{ }^{\circ} \mathrm{C}$. The percentage crystallinity degree was calculated using the equation: $X_{\mathrm{c}}=$ $\Delta H_{\mathrm{f}} \times(100 / 290)$ [15].

The successive self-nucleation and annealing (SSA) experiments were conducted by using a DSC 1 Mettler Toledo instrument at nitrogen atmosphere with the gas flow of $30 \mathrm{~mL} \mathrm{~min}^{-1}$. The samples were heated up to $170{ }^{\circ} \mathrm{C}$ and maintained at this level for $20 \mathrm{~min}$, and then they were cooled down to $0{ }^{\circ} \mathrm{C}$ at the rate of $5^{\circ} \mathrm{C} \mathrm{min}-1$. The heating-annealing-cooling cycles were repeated for temperatures from 140 to $67^{\circ} \mathrm{C}$ at $3{ }^{\circ} \mathrm{C}$ intervals $[16,17]$.

The thickness values for various lamellae can be calculated from the Gibbs-Thomson equation [18]:

$T_{\mathrm{m}}=T_{\mathrm{m}}^{0}\left(\frac{1-2 \sigma_{\mathrm{e}}}{\Delta H_{\mathrm{f}} \cdot L_{\mathrm{GT}}}\right)$

The lamellar thickness $L_{\mathrm{GT}}$ was determined from the peak of each lamellar thickness distribution. The following parametric values were used in calculations [19-21]: $T_{\mathrm{m}}^{0}$-equilibrium melting temperature of a perfect crystal is $145.5^{\circ} \mathrm{C}$, $\Delta H_{\mathrm{f}}$-heat of fusion per unit volume for a perfect crystal is $290 \mathrm{~J} \mathrm{~cm}^{-3}$, and $\sigma_{\mathrm{e}}$-crystallite specific surface free energy is $90 \mathrm{~mJ} \mathrm{~m}^{-2}$.

In turn, the DI values can be obtained through calculation of the ratio of the melting enthalpy $\left(\Delta H_{\mathrm{m}}\right)$ of each peak to the melting enthalpy $\left(\Delta H_{\mathrm{m}}^{\mathrm{max}}\right)$ of the maximum peak in the SSA curves of the copolymer. 


\section{Results and discussion}

\section{Melting and crystallization behavior of E/POSS copolymers synthesized by complexes bearing phenoxy-imine or salen ligands}

In our previous work [3-5], it was found that ethylene/ multi-alkenylsilsesquioxane copolymers synthesized over post-metallocene catalytic systems were characterized by higher POSS incorporation level, as well as higher molecular weight and broad molecular dispersion in comparison with corresponding E/POSS copolymers obtained by ansametallocene. In addition, the content of specific unsaturation groups present in the E/POSS copolymers depended on the kind of post-metallocene complexes used in polymerization process, what was confirmed by FT-IR analysis. Differences in the structure of E/POSS copolymers obtained using bis(phenoxy-imine) Ti, Zr, V, or V salen-type complexes significantly affected their thermal properties.

In this study, we investigated the influence of composition of E/POSS copolymers on their melting and crystallization behavior. Selected ethylene copolymers with POSS-6-2 or POSS-10-3 copolymers synthesized over bis(phenoxyimine) $\mathrm{Ti}, \mathrm{Zr}, \mathrm{V}$, and $\mathrm{V}$ salen-type catalysts were evaluated by differential scanning calorimetry (DSC). The values of the crystallinity degree $\left(X_{\mathrm{c}}\right)$, onset, peak, and endset melting temperatures ( $T_{\mathrm{mo}}, T_{\mathrm{mp}}$ and $T_{\mathrm{me}}$, respectively), and onset, peak, and endset crystallization temperatures $\left(T_{\mathrm{co}}, T_{\mathrm{cp}}\right.$, and $T_{\mathrm{c}}$, respectively) for neat polyethylenes and for E/POSS copolymers are presented in Table 1.

The melting temperatures $\left(T_{\mathrm{mp}}\right)$ for ethylene/POSS copolymers in most cases were lower than that for neat PE (Table 1). The values of $T_{\mathrm{mp}}$ were found generally decreased with the increase of POSS content in copolymer. Noteworthy is that E/POSS copolymers synthesized by bis(phenoxyimine) $\mathrm{Ti}$ and $\mathrm{Zr}$ complexes with low POSS content were characterized by higher $T_{\mathrm{mp}}$ values in comparison with this value for PE (Table 1, items 1, 2, 4, 6, 7, and 9).

It was found that the incorporation of POSS comonomer into the polymer chain resulted in narrowing of endothermal peaks, what could suggest the homogeneity of E/POSS copolymers (Table 1).

It should be noted that crystallinity degrees $\left(X_{\mathrm{c}}\right)$ of E/ POSS copolymers generally decreased with increasing POSS content in the polymer chain regardless of the kind of POSS comonomer used (Table 1), what is associated with the irregular order of macromolecules after incorporation of POSS units.

Table 1 Thermal properties of PE and E/POSS copolymers synthesized over post-metallocene complexes

\begin{tabular}{|c|c|c|c|c|c|c|c|c|c|c|c|c|}
\hline \multirow[t]{2}{*}{ Entry } & \multirow[t]{2}{*}{ Cat } & \multirow[t]{2}{*}{ (Co)polymers } & \multirow[t]{2}{*}{$X_{\mathrm{c}}^{\mathrm{c}} / \%$} & \multicolumn{3}{|c|}{ Melting temperature ${ }^{\mathrm{c}} /{ }^{\circ} \mathrm{C}$} & \multicolumn{3}{|c|}{$\begin{array}{l}\text { Crystallization } \\
\text { temperature }{ }^{\mathrm{c}} /{ }^{\circ} \mathrm{C}\end{array}$} & \multirow[t]{2}{*}{$\Delta T /{ }^{\circ} \mathrm{C}$} & \multirow[t]{2}{*}{$t_{1 / 2} / \min$} & \multirow[t]{2}{*}{$G / \min ^{-1}$} \\
\hline & & & & $T_{\mathrm{mo}}$ & $T_{\mathrm{mp}}$ & $T_{\text {me }}$ & $T_{\text {co }}$ & $T_{\mathrm{cp}}$ & $T_{\mathrm{ce}}$ & & & \\
\hline 1 & $\mathrm{FI}^{-\mathrm{TiH}}{ }^{\mathrm{e} f}$ & $\mathrm{PE}$ & 50.8 & 125.6 & 137.4 & 143.0 & 123.1 & 116.6 & 105.1 & 18.0 & 1.67 & 0.60 \\
\hline $2^{\mathrm{a}}$ & & E/POSS-6-2* & 52.8 & 125.8 & 136.5 & 142.3 & 123.4 & 117.6 & 106.8 & 16.6 & 1.25 & 0.80 \\
\hline $3^{\mathrm{b}}$ & & & 52.5 & 124.8 & 137.3 & 143.3 & 123.1 & 116.6 & 104.4 & 18.7 & 1.42 & 0.70 \\
\hline $4^{\mathrm{a}}$ & & E/POSS-10-3 & 50.5 & 123.7 & 137.1 & 144.1 & 122.8 & 116.9 & 104.6 & 18.2 & 1.63 & 0.61 \\
\hline $5^{\mathrm{b}}$ & & & 45.1 & 124.0 & 138.1 & 141.2 & 122.3 & 116.2 & 105.1 & 17.2 & 1.53 & 0.65 \\
\hline 6 & $\mathrm{FI}-\mathrm{ZrH}^{\mathrm{e}}$ & $\mathrm{PE}$ & 62.7 & 123.1 & 137.9 & 143.7 & 122.7 & 115.7 & 103.7 & 19.0 & 1.70 & 0.59 \\
\hline $7^{\mathrm{a}}$ & & E/POSS-6-2* & 69.6 & 123.6 & 137.7 & 143.2 & 122.8 & 116.9 & 105.5 & 17.3 & 1.32 & 0.76 \\
\hline $8^{\mathrm{b}}$ & & & 59.6 & 123.9 & 136.8 & 142.5 & 122.8 & 117.7 & 107.2 & 15.6 & 1.25 & 0.80 \\
\hline $9^{a}$ & & E/POSS-10-3 & 68.5 & 125.5 & 136.8 & 142.6 & 123.2 & 116.8 & 105.3 & 17.9 & 1.32 & 0.76 \\
\hline $10^{\mathrm{b}}$ & & & 60.6 & 123.4 & 135.6 & 140.4 & 123.1 & 117.2 & 107.4 & 15.7 & 1.33 & 0.75 \\
\hline 11 & $\mathrm{FI}^{-V B u^{\mathrm{d}}}$ & $\mathrm{PE}$ & 58.3 & 125.6 & 137.4 & 143.1 & 121.9 & 116.3 & 107.6 & 14.3 & 1.53 & 0.65 \\
\hline $12^{\mathrm{a}}$ & & E/POSS-6-2 & 53.0 & 124.3 & 135.6 & 138.4 & 125.5 & 118.4 & 111.4 & 14.1 & 2.50 & 0.40 \\
\hline $13^{\mathrm{b}}$ & & & 52.8 & 120.4 & 131.0 & 137.9 & 125.8 & 116.7 & 106.1 & 19.7 & 2.72 & 0.37 \\
\hline $14^{\mathrm{a}}$ & & E/POSS-10-3 & 54.5 & 124.8 & 136.0 & 141.3 & 126.5 & 118.5 & 107.6 & 18.9 & 1.93 & 0.52 \\
\hline $15^{\mathrm{b}}$ & & & 57.8 & 124.8 & 133.6 & 137.9 & 125.1 & 118.8 & 109.9 & 15.2 & 1.62 & 0.62 \\
\hline 16 & Sal-V ${ }^{\mathrm{d}}$ & $\mathrm{PE}$ & 57.6 & 126.4 & 136.6 & 141.9 & 122.1 & 116.8 & 109.2 & 12.9 & 1.42 & 0.70 \\
\hline $17^{\mathrm{a}}$ & & E/POSS-6-2 & 54.7 & 125.1 & 133.2 & 139.2 & 124.8 & 119.0 & 110.5 & 14.3 & 2.32 & 0.43 \\
\hline $18^{\mathrm{b}}$ & & & 51.2 & 123.0 & 133.0 & 136.1 & 125.2 & 117.6 & 104.2 & 21.0 & 2.57 & 0.39 \\
\hline $19^{\mathrm{a}}$ & & E/POSS-10-3 & 52.9 & 123.9 & 129.5 & 136.9 & 125.3 & 115.3 & 111.1 & 14.2 & 2.38 & 0.42 \\
\hline $20^{\mathrm{b}}$ & & & 50.5 & 123.8 & 133.1 & 138.9 & 123.6 & 118.2 & 105.8 & 17.8 & 2.60 & 0.39 \\
\hline
\end{tabular}

[POSS]: ${ }^{\mathrm{a}} 1.67 \times 10^{-3}$ and ${ }^{\mathrm{b}} 6.67 \times 10^{-3} \mathrm{~mol} \mathrm{dm}{ }^{-3}$, data were obtained by ${ }^{\mathrm{c}} \mathrm{DSC}, \mathrm{p}_{\mathrm{e}}={ }^{\mathrm{d}} 0.2$ and ${ }^{\mathrm{e}} 0.5 \mathrm{MPa}, \mathrm{T}_{\mathrm{r}}={ }^{\mathrm{f}} 30^{\circ} \mathrm{C}, 50{ }^{\circ} \mathrm{C}, \mathrm{t}_{\mathrm{r}}=30 \mathrm{~min} . *[3]$ 
In case of E/POSS copolymers obtained by FI-TiH and FI-ZrH catalysts, the peak crystallization temperature values $\left(T_{\mathrm{cp}}\right)$ were generally shifted toward higher temperatures in comparison with neat $\mathrm{PE}$ and increased with increasing content of POSS in copolymer, what indicated that the POSS units effectively accelerated the crystallization process (Table 1, items 1-10).

The changes of $T_{\mathrm{cp}}$ values for E/POSS copolymers synthesized by FI-VBu and Sal-V catalyst were unsystematic (Table 1, items 11-20). The $T_{\mathrm{co}}$ and $T_{\mathrm{ce}}$ values of copolymers obtained by post-metallocene vanadium complexes generally were higher in comparison with neat polyethylene, regardless of kind of POSS used. These results suggested that the crystallization process of those copolymers started early and ran faster than for neat PE (Fig. 3, Table 1, items 11-20).

In order to better understand the influence of POSS units on the crystallization process of E/POSS copolymers, the relative crystallinity of polymer $X$ as a function of time was determined. In addition, we calculate $t_{1 / 2}$ and the growth rate $(G)$ which is the reciprocal of the crystallization half time $G=\left(t_{1 / 2}\right)^{-1}$. The crystallization half time $\left(t_{1 / 2}\right)$ is one of the most interesting and important parameters in the investigation of crystallization kinetics. It is defined as the time required to reach a relative crystallinity of $50 \%$. The $t_{1 / 2}$ can

(a)
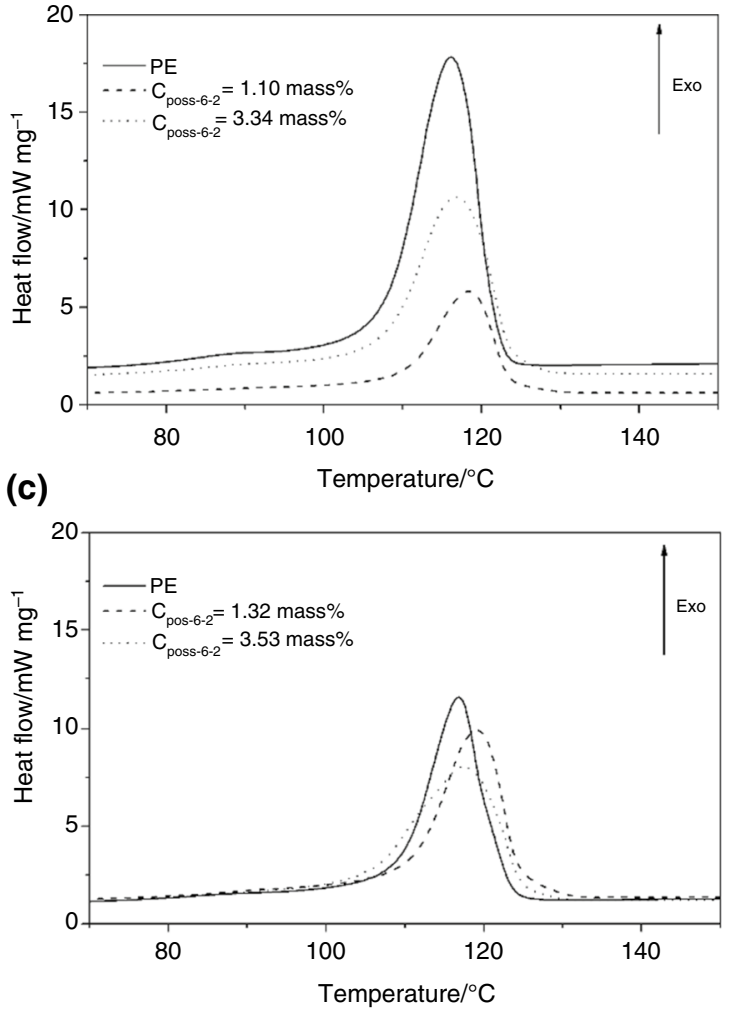

be calculated from equation. $X_{\mathrm{t}}$ and $X_{\mathrm{t} \infty}$ are the relative crystallinity at specific time and infinite time, respectively.

$X=\frac{X_{\mathrm{t}}}{X_{t_{\infty}}}$

In turn, the reciprocal of $t_{1 / 2}$ determines the crystallization rate. In Table 1, are shown the values of $t_{1 / 2}$ and $G$ for all of the obtained polymeric products. It should be noted that the ethylene copolymers with multi-alkenylsilsesquioxanes synthesized by FI-TiH and especially FI-ZrH complexes were characterized by higher the crystallization rate in comparison with neat polyethylene (Table 1, items 1-10). These results confirmed the influence of POSS derivatives on the crystallization rate of copolymers as a nucleating agent.

\section{Thermal stability of E/POSS copolymers}

The structure of ethylene copolymers with multi-alkenylsilsesquioxane comonomers should also affect the thermal stability of such materials. We found here that the linear copolymers of ethylene with POSS-6-2 and E/POSS-10-3 obtained under $0.5 \mathrm{MPa}$ were characterized by a significantly higher thermal stability than polyethylene as evidenced by higher values of $T_{5}, T_{30}$, and $T_{\max }$ (Table 2, items 1-10).

(b)
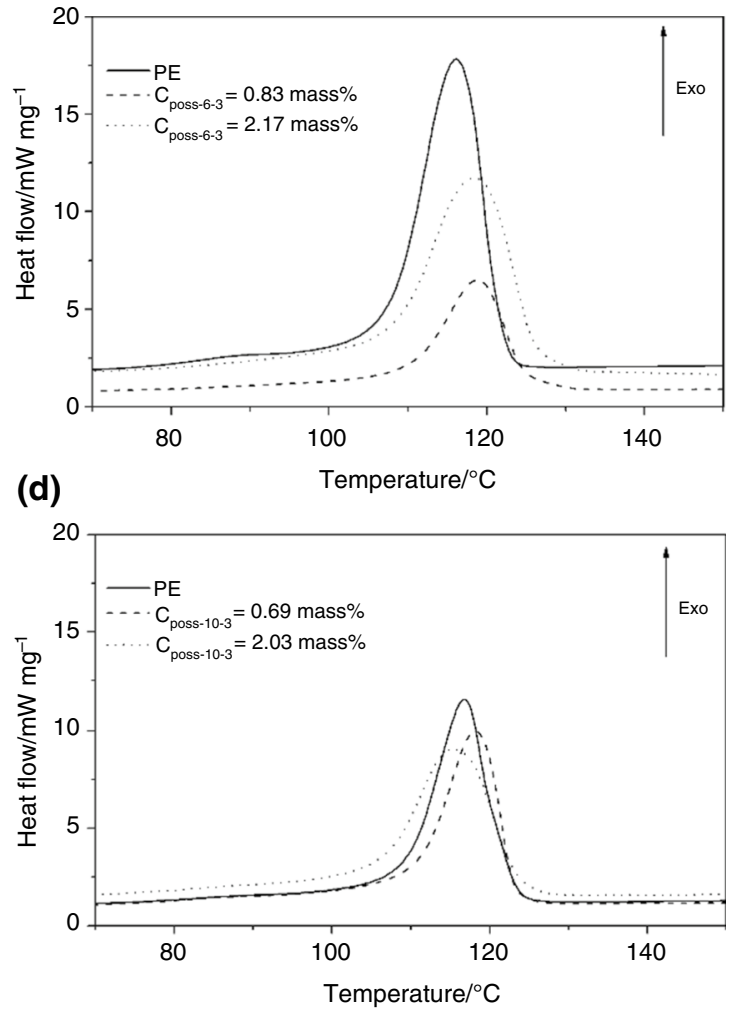

Fig. 3 The DSC curves of polyethylene, E/POSS-6-2, and E/POSS-10-3 copolymers obtained by FI-VBu (a, b) and Sal-V (c, d) 
Table 2 Physicochemical properties for ethylene/POSS copolymers obtained over bis(phenoxy-imine) Ti, Zr, V and V salen-type complexes

\begin{tabular}{|c|c|c|c|c|c|c|c|c|c|c|c|}
\hline \multirow[t]{2}{*}{ Item } & \multirow[t]{2}{*}{ Catalyst } & \multirow[t]{2}{*}{ (Co)polymers } & \multirow[t]{2}{*}{$p_{\mathrm{e}} / \mathrm{MPa}$} & \multirow[t]{2}{*}{$\begin{array}{l}\mathrm{C}_{\mathrm{POSS}}{ }^{* /} \\
\text { mass } \%\end{array}$} & \multirow[t]{2}{*}{$T_{5} /{ }^{\circ} \mathrm{C}$} & \multirow[t]{2}{*}{$T_{30}{ }^{\circ} \mathrm{C}$} & \multirow[t]{2}{*}{$T_{\max } /{ }^{\circ} \mathrm{C}$} & \multirow[t]{2}{*}{$M_{\mathrm{w}} \times 10^{-3 *} / \mathrm{g} \mathrm{mol}^{-1}$} & \multirow[t]{2}{*}{$M_{\mathrm{w}} * / M_{\mathrm{n}}$} & \multicolumn{2}{|c|}{$\begin{array}{l}\text { Unsaturation } \\
\text { groups* }\end{array}$} \\
\hline & & & & & & & & & & $\mathrm{A}_{908 / 2020}$ & $\mathrm{~A}_{800 / 2020}$ \\
\hline 1 & FI-TiH & $\mathrm{PE}$ & 0.5 & 0 & 397.0 & 457.0 & 468.1 & 1050 & 12.7 & 0.231 & 0 \\
\hline $2^{\mathrm{a}}$ & & E/POSS-6-2 & & 4.01 & 363.3 & 450.5 & 471.4 & 946 & 4.1 & 0.321 & 0.259 \\
\hline $3^{\mathrm{b}}$ & & & & 7.57 & 379.6 & 452.6 & 472.6 & 558 & 3.6 & 0.534 & 0.520 \\
\hline $4^{\mathrm{a}}$ & & E/POSS-10-3 & & 1.03 & 392.6 & 447.4 & 470.9 & - & - & 0.577 & 0.196 \\
\hline $5^{\mathrm{b}}$ & & & & 1.75 & 376.8 & 448.5 & 462.0 & - & - & 0.697 & 0.428 \\
\hline 6 & FI-ZrH & $\mathrm{PE}$ & & 0 & 300.9 & 426.8 & 458.4 & 1135 & 7.1 & 0.298 & 0 \\
\hline $7^{\mathrm{a}}$ & & E/POSS-6-2 & & 1.48 & 378.1 & 436.8 & 461.8 & 358 & 8.3 & 0.668 & 0.334 \\
\hline $8^{\mathrm{b}}$ & & & & 5.09 & 386.3 & 435.9 & 460.3 & 198 & 5.6 & 1.180 & 1.764 \\
\hline $9^{\mathrm{a}}$ & & E/POSS-10-3 & & 1.03 & 387.0 & 432.4 & 468.1 & 572 & 11.6 & 0.902 & 0.196 \\
\hline $10^{\mathrm{b}}$ & & & & 1.22 & 347.0 & 433.3 & 468.6 & - & - & 1.037 & 0.428 \\
\hline 11 & FI-VBu & $\mathrm{PE}$ & 0.2 & 0 & 347.5 & 435.7 & 468.2 & 348 & 1.5 & 0.251 & 0 \\
\hline $12^{\mathrm{b}}$ & & E/POSS-6-2 & & 3.34 & 310.8 & 438.9 & 463.9 & 180 & 3.8 & 0.407 & 0.043 \\
\hline $13^{\mathrm{b}}$ & & E/POSS-10-3 & & 2.17 & 313.8 & 429.2 & 458.7 & 228 & 4.1 & 0.557 & 0.918 \\
\hline 14 & Sal-V & $\mathrm{PE}$ & & 0 & 360.4 & 425.0 & 461.7 & 364 & 1.8 & 0.216 & 0 \\
\hline $15^{\mathrm{b}}$ & & E/POSS-6-2 & & 3.53 & 304.7 & 432.5 & 463.2 & 577 & 1.6 & 0.472 & 0.923 \\
\hline $16^{\mathrm{b}}$ & & E/POSS-10-3 & & 2.03 & 316.5 & 430.7 & 454.9 & 164 & 5.7 & 0.505 & 0.722 \\
\hline
\end{tabular}

Concentration of POSS in reaction feed: ${ }^{\mathrm{a}} 1.67 \times 10^{-3} \mathrm{~mol} \mathrm{dm}^{-3},{ }^{\mathrm{b}} 6.67 \times 10^{-3} \mathrm{~mol} \mathrm{dm}^{-3}$, reaction time: 30 min. The measurement was carried out at a heating rate of $10{ }^{\circ} \mathrm{C} \min ^{-1}$ from 25 to $500{ }^{\circ} \mathrm{C}$ in air. *[4, 5]

However, the FI-ZrH complexes allowed to obtain (co) polymers characterized by the highest thermal stability out of all polymeric products synthesized by post-metallocene catalysts studied (Table 2, items 1-10). Moreover, thermal stability of ethylene copolymers with di-alkenylsilsesquioxanes (POSS-6-2) improved markedly with the increasing content of POSS comonomer regardless of the type of catalyst (Table 2, items 2 and 3, and 7 and 8).

E/POSS copolymers obtained by the bis(phenoxy-imine) zirconium and titanium catalytic systems were characterized by higher thermal stability than monoalkenyl- and monoalkenyl(siloxy)silsesquioxanes obtained over rac$\mathrm{Et}(\mathrm{Ind})_{2} \mathrm{ZrCl}_{2}$ [1]. Noteworthy is that the values of $T_{5}$ and $T_{30}$ of the copolymers E/POSS obtained in the presence of post-metallocene catalyst were usually lower than for neat polyethylene, regardless of the kind and share of POSS comonomer used. However, the FI-TiH and FI-ZrH complexes allowed to obtain (co)polymers characterized by the highest thermal stability out of all polymeric products synthesized by post-metallocene catalysts studied (Table 2 , items 1-10).

In case of copolymers produced by the FI-ZrH/MAO catalytic system, a significant increase was found in $T_{5}$ parameter, even by $46.1-86.1{ }^{\circ} \mathrm{C}$, depending on the kind and content of multi-alkenyl POSS in copolymer, in comparison with neat polyethylene (Table 2, items 6-10, Fig. 4a, b). It could thus be concluded that incorporation of POSS units increased the initial temperature of thermal decomposition of copolymer materials. However, changes in $T_{30}$ parameter were less significant (Table 2, items 6-10).

The high thermal stability of E/POSS copolymers could be explained by possible formation of a ceramic layer on the surface of the materials during thermal degradation of POSS units. These phenomena could be explained by limitation of the heat flux to the sample, oxygen diffusion toward the copolymers, and the volatile degradation gases from the sample [15].

Meanwhile, the increase in POSS-10-3 content resulted in a significant reduction in the thermal stability of its copolymer with ethylene. It should be noted that POSS-10-3 comonomer contained incompletely condensed silicon-oxygen cage $T_{4} D_{3}$ clearly more susceptible to degradation in contrast to POSS-6-2 with fully condensed cage $\mathrm{T}_{8}$.

In turn, post-metallocene vanadium complexes (bearing phenoxy-imine and salen-type ligands) used for ethylene copolymerization with POSS performed under $p_{\mathrm{e}}=0.2 \mathrm{MPa}$ resulted in obtaining copolymers characterized by the lowest values of the characteristic parameters (Table 2, items 11-16). These copolymers proved to be less thermally stable than neat polyethylene and other samples of E/POSS copolymers studied irrespective of POSS comonomer type.

It should be noted that significant differences in thermal stability of obtained E/POSS copolymers could be explained by different contents of POSS units in the copolymer macromolecules, the $M_{\mathrm{w}}$ values of E/POSS copolymers, and also by specific POSS-POSS interactions and 
(a)

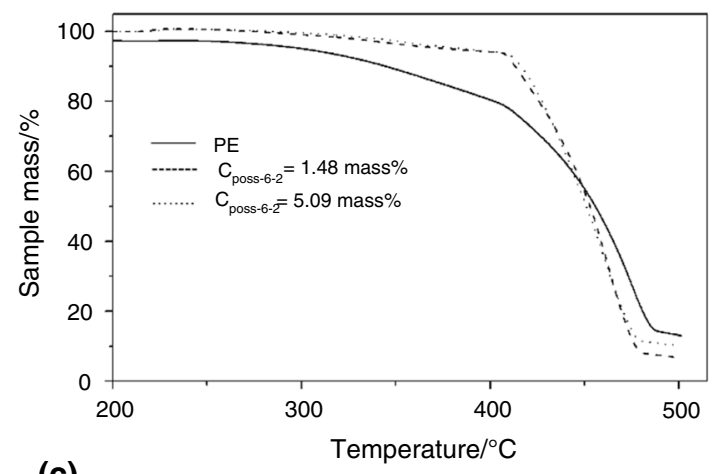

(c)

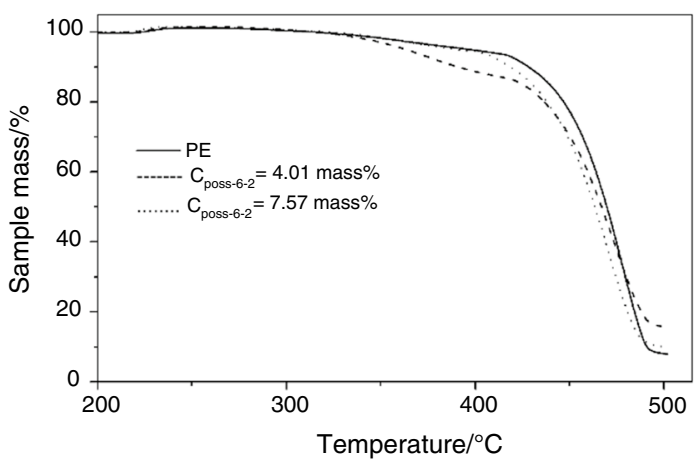

(b)

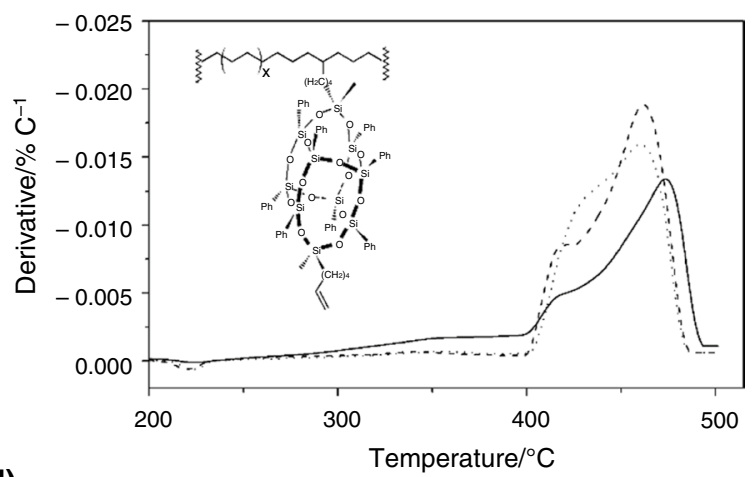

(d)

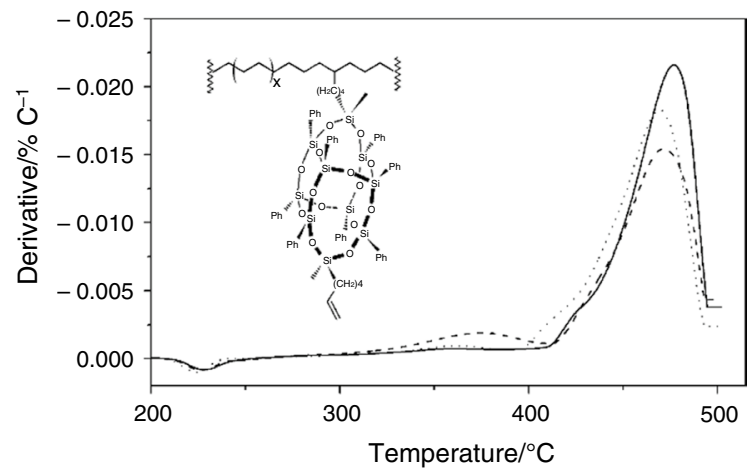

Fig. 4 TGA and DTA curves of polyethylene and E/POSS-6-2 copolymers synthesized by FI-ZrH (a, b) and FI-TiH (c, d) complexes

POSS-polyethylene sequences, which was associated with different distributions of POSS units in the copolymer materials (Table 2). However, noteworthy is that E/POSS copolymers synthesized by $\mathrm{V}$ salen-type complex, despite the fact that they contained a similar POSS incorporation level $\left(\mathrm{C}_{\text {POSS-10-3 }}=2.03\right.$ mass $\%$ and $\mathrm{C}_{\text {POSS-6-2 }}=3.53$ mass $\%$, respectively) and content of unsaturation groups (vinyl end group 0.505 and 0.472 , trisubstituted vinylene 0.722 and 0.923 , respectively), were characterized by different thermal stability (Table 2, items 15 and 16). The $T_{5}$ value of E/ POSS-10-3 was higher by $15^{\circ} \mathrm{C}$ than this TGA parameter for E/POSS-6-2 copolymer, although the former contained a not fully condensed cage. Despite a similar way of incorporation of POSS comonomers (as a side group of the main chain), the thermal stability of E/POSS copolymers differed considerably and was dependent on the type of catalyst used.

In order to understand the effect of POSS incorporation into the polymer chain as a side group by different complexes bearing phenoxy-imine and salen ligands on thermal stability, unsaturation group analysis was performed [5]. The content of specific unsaturation groups in E/POSS copolymers was found to influence significantly on the thermal stability of obtained polymeric products. It should be noted that the $\mathrm{C}=\mathrm{C}$ bonds in the main chain due to their high reactivity toward oxygen resulted in the degradation process of polymeric products. The content of $\mathrm{C}=\mathrm{C}$ bonds (vinyl and trisubstituted vinylene groups) occurring in E/POSS copolymers increased, depending on the type of catalyst used as follows: FI-TiH $>$ FI-ZrH $>$ FI-VBu $\sim$ Sal-V (Table 2). These results were in line with the thermal stability evaluated by the study of thermogravimetric analysis (Table 2). Interesting is that the content of trisubstituted vinylene groups (internal unsaturations) present in E/POSS copolymers obtained by both vanadium complexes was generally much higher in comparison with the content of specific unsaturation groups in copolymers obtained using bis(phenoxyimine) titanium and zirconium complexes (Table 2).

\section{Thermal stability and heterogeneity of E/POSS copolymers}

In order to explain the differences in thermal properties for E/POSS copolymers synthesized by bis(phenoxy-imine) zirconium and $\mathrm{V}$ salen-type complexes with a similar incorporation level and content of unsaturation groups, SSA analysis was performed. Already in the above described studies of copolymer crystallization were found that the increasing content of POSS in copolymer chain resulted in broadening of the exothermic peak corresponding to the polymer crystallization process (Fig. 3, Table 1, items 11-20) in 
contrast to products obtained by FI-TiH and FI-ZrH catalysts (Table 1, items 1-10). It could be thus concluded that copolymers obtained by post-metallocene vanadium catalysts (FI$\mathrm{VBu}$ and $\mathrm{Sal}-\mathrm{V}$ ) were characterized by more heterogeneous compositions (Table 1, items 11-20).

SSA analysis confirmed that the ethylene copolymers with di- or tri-alkenylsilsesquioxane obtained by FI-ZrH contained relatively homogeneous compositions independently of the comonomer incorporation level (Fig. 5 a).

In turn, the copolymers obtained by $\mathrm{V}$ salen-type complex were characterized by multiple melting peaks which were observed in the SSA curves of copolymer samples, although they were characterized by a comparable and even smaller incorporation degree of POSS units than copolymers obtained by FI-ZrH (Fig. 5 b). Moreover, there was also observed a difference in the number of peaks, their location, and intensity (Fig. 5).
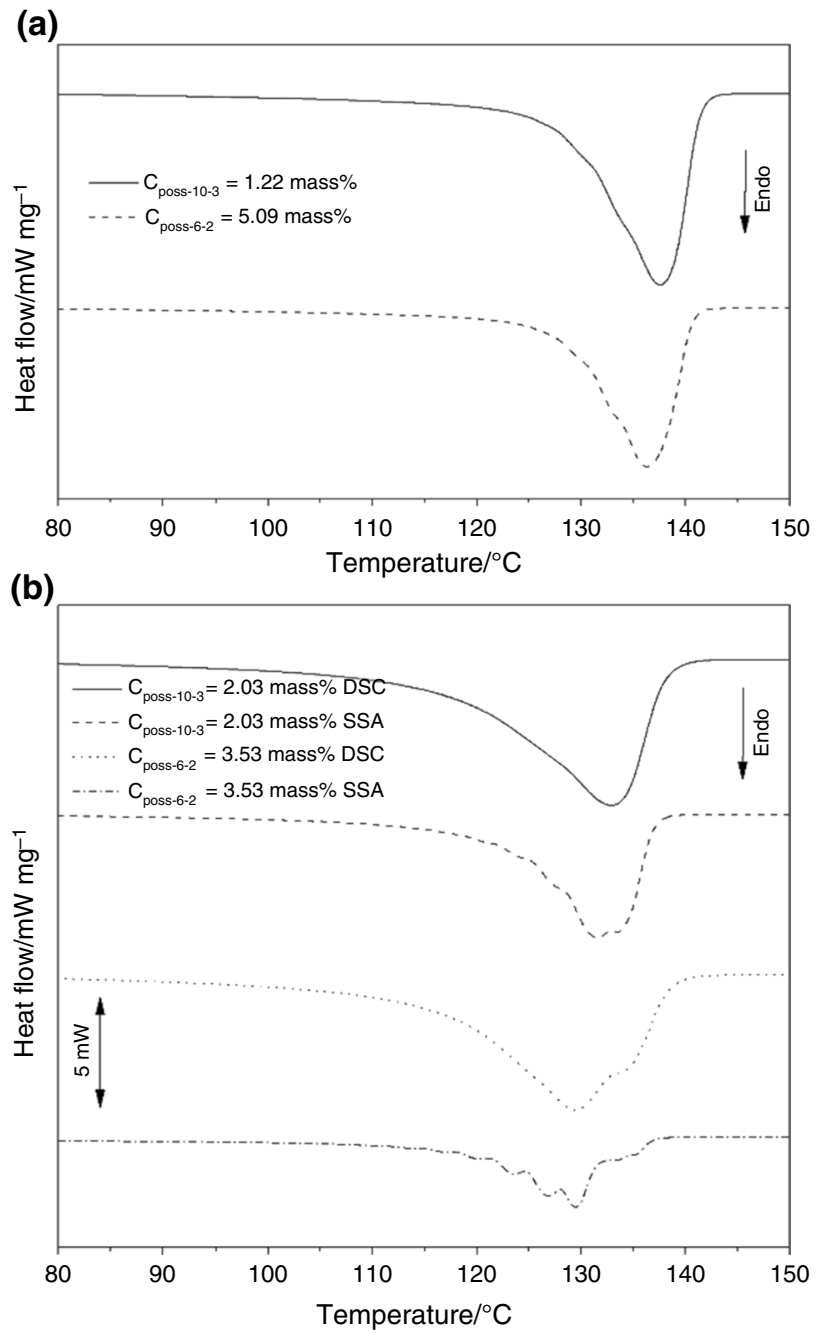

Fig. 5 Comparison of SSA curves of ethylene copolymers with POSS-6-2 or POSS-10-3 comonomer obtained by complex: bis(phenoxy-imine) zirconium (a) or V salen-type (b)
The V salen-type/ $\mathrm{Et}_{2} \mathrm{AlCl}$ catalytic system produced $\mathrm{E} /$ POSS copolymers with seven and eleven thermal fractionation melting peaks in the range $104-135{ }^{\circ} \mathrm{C}$ and $102-136{ }^{\circ} \mathrm{C}$ for E/POSS-10-3 and E/POSS-6-2, respectively (Fig. 5). Those results indicated that the composition of E/POSS-6-2 copolymer $\left(\mathrm{C}_{\mathrm{POSS}}=3.53\right.$ mass $\left.\%\right)$ was much more heterogeneous in comparison with hybrid materials with a slightly lower POSS-10-3 content $\left(\mathrm{C}_{\text {POSS }}=2.03\right.$ mass $\left.\%\right)$. For evaluation of the heterogeneity of hybrid materials, the concept of dispersity index (DI) was very often used [22-24] (Fig. 6).

The DI values calculated for each separated peak were different, although greater dissimilarity was observed for E/POSS-6-2 copolymer, what is associated with the heterogeneity of comonomer distribution along the main chain [22]. The DI values clearly indicated that the E/POSS-6-2 copolymer was more heterogeneous in comparison with $\mathrm{E} /$ POSS-10-3, while both were obtained by vanadium catalyst. It should be explained that ethylene/POSS-6-2 copolymers contained shorter ethylene sequence lengths which recrystallized in shorter lamellar; therefore, many additional peaks appeared in the SSA curves due to the segregation of the crystallizable sequence lengths.

The relative share of lamellas with different thicknesses was determined by the $\Delta H_{\mathrm{m}}$ values for each peak in the SSA curves (Fig. 6). It should be noted that neat E/POSS10-3 samples had narrow distribution of lamellar thickness in the range from 7.5 to $30.7 \mathrm{~nm}$ and the highest fraction

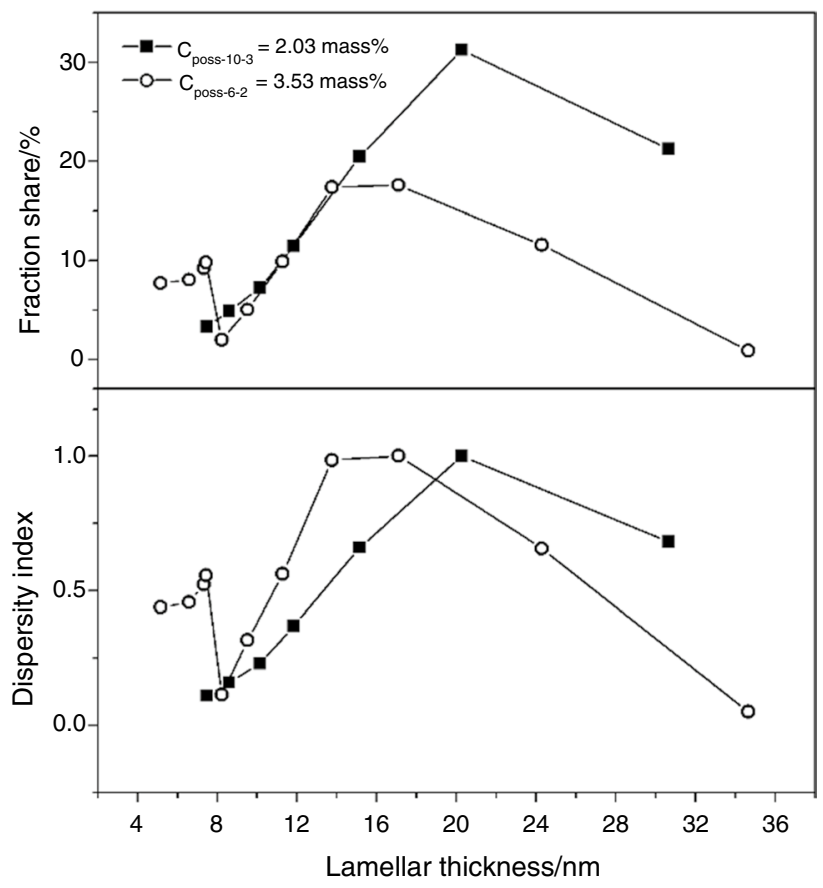

Fig. 6 Comparison of lamellar thickness with different DI values and fraction share for E/POSS copolymers synthesized over V salen-type complex 
occurred at lamellar thicknesses $\left(l_{\mathrm{n}}\right)$ around $20.3 \mathrm{~nm}$ in contrast to E/POSS-6-2 copolymers which contained the lamellar size from 5.2 to $34.6 \mathrm{~nm}$ with the highest fraction at $l_{\mathrm{n}}=17.1 \mathrm{~nm}$. In addition, the $\mathrm{V}$ salen-type complex allowed to obtain the E/POSS-6-2 copolymers with larger lamellar size in contrast to $\mathrm{rac}$-Et(Ind) ${ }_{2} \mathrm{ZrCl}_{2} / \mathrm{MAO}$ catalytic system $\left(l_{\mathrm{n}}=4.6-16.9 \mathrm{~nm}\right)[3]$.

It should be noted that fraction was characterized by the lowest lamellar thicknesses, what could be assigned to selfaggregation of POSS. This phenomenon was confirmed by our previous findings [7].

The more heterogeneous composition of E/POSS-6-2 copolymers obtained by V-catalysts resulted in their lower thermal stability compared to E/POSS-10-3 counterparts, although the latter contained less stable incompletely condensed silicon-oxygen cage. These results were in line with the thermal stability evaluated by TGA method (Table 2 , items 12 and 13 as well as 15 and 16).

\section{Conclusions}

Thermal properties of ethylene copolymers with di- and trialkenylsilsesquioxanes synthesized by bis(phenoxy-imine) $\mathrm{Ti}, \mathrm{Zr}, \mathrm{V}$, and V salen-type complexes were investigated in detail by DSC and TGA techniques. All these copolymers contained silsesquioxane comonomers only as side groups of the main chain, regardless of comonomer functionality. The kind and content of multi-alkenylsilsesquioxane units incorporated into the polymer chain, as well as the structure of macromolecules, significantly influenced on thermal stability of obtained copolymers.

The peak melting temperature $\left(T_{\mathrm{mp}}\right)$ of copolymers obtained by bis(phenoxy-imine) Ti, Zr, V, and V salen-type complexes generally decreased with increasing POSS content. However, lower POSS incorporation level in copolymers synthesized by bis(phenoxy-imine) titanium and zirconium complexes caused a significant shift of $T_{\mathrm{mp}}$ values toward higher temperature than polyethylene. These results were associated with a strong interaction between POSS units and polyethylene sequences.

The crystallinity degree $\left(X_{\mathrm{c}}\right)$ of copolymers obtained over bis(phenoxy-imine) $\mathrm{Ti}$ and $\mathrm{Zr}$ catalysts was generally higher than for neat polyethylene in contrast to the copolymers synthesized over both vanadium catalysts that showed less crystallinity compared to polyethylene.

The E/POSS copolymers synthesized by FI-TiH and FI$\mathrm{ZrH}$ complexes were characterized by higher crystallization rate in comparison with neat polyethylene, what confirmed the influence of POSS derivatives on the crystallization rate of copolymers as a nucleating agent.

Thermal stability of E/POSS copolymers generally increased with increasing content of silsesquioxane comonomers. However, this feature was dependent not only on the kind and content of silsesquioxane but also on POSS distribution in main copolymeric chains and the content of specific unsaturation groups. Thermal stability of E/POSS copolymers decreased with increasing content of trisubstituted vinylene groups, regardless of the kind of organometallic complexes used.

The heterogeneity of macromolecules was found to significantly influence on thermal stability of E/POSS copolymers. E/POSS-6-2 and E/POSS-10-3 copolymers obtained by $\mathrm{V}$ salen-type complex despite a similar POSS incorporation level and content of unsaturation groups markedly varied in heterogeneity. E/POSS-6-2 copolymer was found to be more heterogeneous than E/POSS-10-3 copolymer, what is related to lower thermal stability of this material.

Acknowledgements The authors are grateful to Professor Abdollah Omrani (Faculty of Chemistry, University of Mazandaran, Iran) for his assistance in calculation of crystallization kinetics. This work was financially supported by the National Science Centre of Poland (NCN), under the OPUS 4 research scheme, Grant Number: DEC-2012/07/B/ ST5/03042.

Open Access This article is licensed under a Creative Commons Attribution 4.0 International License, which permits use, sharing, adaptation, distribution and reproduction in any medium or format, as long as you give appropriate credit to the original author(s) and the source, provide a link to the Creative Commons licence, and indicate if changes were made. The images or other third party material in this article are included in the article's Creative Commons licence, unless indicated otherwise in a credit line to the material. If material is not included in the article's Creative Commons licence and your intended use is not permitted by statutory regulation or exceeds the permitted use, you will need to obtain permission directly from the copyright holder. To view a copy of this licence, visit http://creativecommons.org/licenses/by/4.0/.

\section{References}

1. Groch P, Dziubek K, Czaja K, Grzymek M. Investigation of thermal stability of ethylene copolymers with POSS - Study under static and dynamic conditions. Polym Degrad Stab. 2018;156:218-27. https://doi.org/10.1016/j.polymdegradstab .2018.09.010.

2. Niemczyk A, Dziubek K, Sacher-Majewska B, Czaja K, Dutkiewicz M, Marciniec B. Study of thermal properties of polyethylene and polypropylene nanocomposites with long alkyl chain-substituted POSS fillers. J Therm Anal Calorim. 2016;125(3):1287-99. https://doi.org/10.1007/s10973-016-5497-4.

3. Groch P, Dziubek K, Czaja K, Mituła K, Dudziec B. Multi-alkenylsilsesquioxanes as comonomers and active species modifiers of metallocene catalyst in copolymerization with ethylene. Polymers. 2018;10(2):223. https://doi.org/10.3390/polym10020223.

4. Groch P, Dziubek K, Czaja K, Białek M, Mituła K, Dudziec $\mathrm{B}$, et al. Synthesis and structural characterization of ethylene copolymers containing double-decker silsesquioxane as pendant groups and cross-linkage sites by coordinative copolymerization. Eur Polym J. 2018;100:187-99. https://doi.org/10.1016/j.eurpo lymj.2018.01.039. 
5. Groch P, Dziubek K, Czaja K, Białek M, Man D. Tri-alkenyl polyhedral oligomeric silsesquioxanes as comonomers and active center modifiers in ethylene copolymerization catalyzed by bis(phenoxy-imine) $\mathrm{Ti}, \mathrm{Zr}, \mathrm{V}$ and $\mathrm{V}$ salen-type complexes. Appl Catal A. 2018;567:122-31. https://doi.org/10.1016/j.apcat a.2018.09.011.

6. Groch P, Dziubek K, Czaja K, Dudziec B, Marciniec B. Copolymers of ethylene with monoalkenyl- and monoalkenyl(siloxy) silsesquioxane (POSS) comonomers - synthesis and characterization. Eur Polym J. 2017;90:368-82. https://doi.org/10.1016/j. eurpolymj.2017.03.038.

7. Groch P, Dziubek K, Czaja K, Białek M, Adamczyk-Tomiak $\mathrm{K}$, Rabiej S, et al. Ethylene/POSS copolymerization behavior of postmetallocene catalysts and copolymer characteristics. J Polym Sci Part A Polym Chem. 2017;55(23):3918-34. https:// doi.org/10.1002/pola.28778.

8. Tsuchida A, Bolln C, Sernetz FG, Frey H, Mülhaupt R. Ethene and propene copolymers containing silsesquioxane side groups. Macromolecules. 1997;30(10):2818-24. https://doi.org/10.1021/ ma960846g.

9. Żak P, Dudziec B, Dutkiewicz M, Ludwiczak M, Marciniec B, Nowicki M. A new class of stereoregular vinylene-arylene copolymers with double-decker silsesquioxane in the main chain. J Polym Sci Part A Polym Chem. 2016;54(8):1044-55. https://doi. org/10.1002/pola.27957.

10. Teng S, Qiu Z. Enhanced crystallization and mechanical properties of biodegradable poly(ethylene succinate) by octaisobutylpolyhedral oligomeric silsesquioxanes in their nanocomposites. Thermochim Acta. 2017;649:22-30. https://doi.org/10.1016/j. tca.2017.01.004.

11. Barbosa R, Alves TS, Araújo EM, Mélo TJA, Camino G, Fina A, et al. Flammability and morphology of HDPE/clay nanocomposites. J Therm Anal Calorim. 2014;115(1):627-34. https://doi. org/10.1007/s10973-013-3310-1.

12. Zhang W, Camino G, Yang R. Polymer/polyhedral oligomeric silsesquioxane (POSS) nanocomposites: an overview of fire retardance. Prog Polym Sci. 2017;67:77-125. https://doi. org/10.1016/j.progpolymsci.2016.09.011.

13. Zhang H-X, Shin Y-J, Yoon K-B, Lee D-H. Preparation and properties of propylene/POSS copolymer with $r a c$-Et(Ind) ${ }_{2} \mathrm{ZrCl}_{2}$ catalyst. Eur Polym J. 2009;45(1):40-6. https://doi.org/10.1016/j. eurpolymj.2008.09.029.

14. Zhang H-X, Jung M-S, Shin Y-J, Yoon K-B, Lee D-H. Preparation and properties of ethylene/POSS copolymer with rac$\mathrm{Et}(\mathrm{Ind})_{2} \mathrm{ZrCl}_{2}$ catalyst. J Appl Polym Sci. 2009;111(6):2697-702. https://doi.org/10.1002/app.29284.

15. Widman G, Riesen R. Thermal analysis: terms, methods, application. Heidelberg: Alfred Huthing Verlag; 1987.
16. Białek M, Czaja K, Sacher-Majewska B. Studies of structural composition distribution heterogeneity in ethylene/1-hexene copolymers using thermal fractionation technique (SSA): effect of catalyst structure. Thermochim Acta. 2005;429(2):149-54. https ://doi.org/10.1016/j.tca.2005.03.011.

17. Czaja K, Sacher B, Białek M. Studies of intermolecular heterogeneity distribution in ethylene/1-hexene copolymers using DSC method. J Therm Anal Calorim. 2002;67(3):547-54. https://doi. org/10.2023/A:1014384116890.

18. Hosoda S. Structural distribution of linear low-density polyethylenes. Polym J. 1988;20(5):383-97. https://doi.org/10.1295/polym j.20.383.

19. Atiqullah M, Adamu S, Malaibari ZO, Al-Harthi MA, Emwas AHM. (nBuCp) ${ }_{2} \mathrm{ZrCl}_{2}$-catalyzed ethylene-4M1P copolymerization: copolymer backbone structure, melt behavior, and crystallization. AlChE J. 2016;62(5):1688-06. https://doi.org/10.1002/ aic. 15159 .

20. Crist B, Howard PR. Crystallization and melting of model ethylene-butene copolymers. Macromolecules. 1999;32(9):3057-67. https://doi.org/10.1021/ma9816362.

21. Zhou H, Wilkes GL. Comparison of lamellar thickness and its distribution determined from d.s.c, SAXS, TEM and AFM for high-density polyethylene films having a stacked lamellar morphology. Polymer. 1997;38(23):5735-47. https://doi.org/10.1016/ S0032-3861(97)00145-6.

22. Starck P, Löfgren B. Thermal properties of ethylene/long chain $\alpha$-olefin copolymers produced by metallocenes. Eur Polym J. 2002;38(1):97-107. https://doi.org/10.1016/S0014 -3057(01)00174-4.

23. Mortazavi SMM, Arabi H, Zohuri G, Ahmadjo S, Nekoomanesh M, Ahmadi M. Copolymerization of ethylene/ $\alpha$-olefins using bis(2-phenylindenyl)zirconium dichloride metallocene catalyst: structural study of comonomer distribution. Polym Int. 2010;59(9):1258-65. https://doi.org/10.1002/pi.2859.

24. Ahmadjo S, Arabi H, Zohuri G, Nekoomanesh M, Nejabat G, Mortazavi SMM. Preparation of ethylene/ $\alpha$-olefins copolymers using (2-RInd)2ZrCl2/MCM-41 (R:Ph, H) catalyst, microstructural study. J Therm Anal Calorim. 2014;116(1):417-26. https:// doi.org/10.1007/s10973-013-3552-y.

Publisher's Note Springer Nature remains neutral with regard to jurisdictional claims in published maps and institutional affiliations. 